\title{
O ensino não-formal como um dos fatores determinantes da qualidade de vida
}

\section{Informal education as one of the quality of life determinant factors}

Jair Antonio de Carvalho ${ }^{1}$

Marlene Pedrote de Carvalho ${ }^{2}$

Fábio Aguiar Alves ${ }^{3}$

Maria Auxiliadora Motta Barreto

\section{Resumo}

Trabalho realizado com aval do Comitê de Ética e Pesquisa (CoEPS), processo número 05/09 (CAAE 0042.0.446.000-10) de 15/03/09, com o objetivo de promover reflexão sobre o ensino não-formal, despertando nos educadores, a importância de melhorar a qualidade de vida das populaçóes. Vários autores afirmam que estamos na era da comunicação. Sabe-se que a mídia tem evoluído muito nos últimos anos, evidenciando a importância das redes sociais que, a cada dia, chega a um número maior de pessoas. Não se pode ignorar o valor deste meio de comunicaçáo que, ainda é privilégio de poucos. Portanto, faz-se necessária a aplicação de medidas educativas como a realização de palestras, oficinas, divulgação através de folders e elaboração de material didático, destinado a levar conhecimentos básicos sobre a alimentação, a fim de facilitar o trabalho dos educadores, bem como o entendimento da populaçâo envolvida. Foi elaborada uma ferramenta didática, com foco em Alimentação saudável, a fim de levar às comunidades carentes, conhecimentos básicos sobre a questão alimentar. Foi realizado um trabalho de validação numa Escola municipal de ensino fundamental, de um bairro de classe média baixa. Na avaliação do conteúdo, os dados obtidos foram: 68,26\% de excelência para a variável adequação; 65,88\% para relevância; 51,92\% para apresentação e 50,96 para clareza.

Pavavras-chave: Ensino não-formal; Informação; Alimentação saudável; Qualidade de vida.

\section{Abstract}

Study conducted with approval of the Ethics and Research (CoEPS), case number 09/05 (CAAE 0042.0.446.00010) of 15/03/09, with the aim to promote reflection on teaching non-formal educators in raising the importance of improving the quality of living. Several authors have stated that we are in the era of communication. It is known that the media has evolved tremendously in recent years, highlighting the importance of social networks, reaching a larger number of people every day. One can not ignore the value of this medium that is still the privilege of few. Therefore, it is necessary to implement measures such as educational lectures, workshops, brochures and dissemination through the development of instructional materials designed to bring basic knowledge about food in order to facilitate the work of educators, as well as the understanding of the population involved. It was developed a teaching tool, with a focus on Healthy eating in order to lead to poor communities, basic knowledge about the food issue. We conducted a validation study in a municipal elementary school from a lower middle class neighborhood. In evaluating the content, the data obtained were $68.26 \%$ of excellence for the variable adequacy, relevance to 65.88\%, 51.92\% and 50.96 for the presentation for clarity.

Keywords: Informal education; Information; Healthy Eating; Quality of life.

1 Mestre em Ensino de Ciências da Saúde e do Meio Ambiente - UniFOA

2 Esp. Recursos Humanos - UBM

3 Doutor. Professor da Universidade Federal Fluminense, Programa de Mestrado em Patologia.

4 Prof. Dra. Programa de Mestrado profissional em Ensino em Ciências da Saúde e do meio ambiente - UniFOA 


\section{INTRODUÇÃO}

Trabalhar com a diversidade é elemento fundamental para o crescimento, tanto do aprendiz quanto do orientador da aprendizagem, portanto, a troca é a base desta relação educacional. O que significa considerar as diferenças como algo que seja motivo de trocas, propício para o crescimento dos indivíduos envolvidos. (VAZ et al 2005).

Como o mundo está envelhecendo, torna-se indispensável cuidar da criança, do jovem e do adulto para que o mesmo se torne um idoso mais capaz, retardando o máximo possível o aparecimento das disfunçóes próprias da idade.

Pereira et al, (2011) relata que, apesar dos avanços tecnológicos contemporâneos, a prevenção de doenças e a promoçáo da saúde, permanecem como pilares para a manutenção da vida. A articulação da educação e saúde possibilita a assistência integral às pessoas quando realizadas por meio de açốes coletivas.

Nos últimos anos, em todos os países, vêm sendo difundidas açôes de ensino para adultos, envolvendo todos os setores da sociedade, desde os não alfabetizados até os profissionais que ostentam os mais altos níveis de titulação acadêmica. Tais açôes envolvem propósitos de crescimento pessoal como cidadãos, melhor desempenho profissional e, em outros casos, até mesmo uma questão de status. A estas diversas formas, áreas e propósitos do ensino convencionou-se chamar de formação continuada. (MALGLAIVE, 2003). Para Libâneo (2007), as práticas educativas não se restringem à escola ou à família.

Segundo Bellan, 2005, o adulto é aquela pessoa madura o suficiente para assumir as responsabilidades por seus atos diante da sociedade, que tem consciência de suas açóes e toma decisões responsáveis. Podemos extrapolar estas açóes e decisóes para o aprendizado, já que estes indivíduos apresentam posturas e maturidade diferenciadas para um melhor discernimento e capacidade de avaliação dos conteúdos ministrados pelos facilitadores.

Segundo Pinto (2007, p 29):

A educação é o processo pelo qual a sociedade forma seus membros à sua imagem e em função de seus interesses.

A relação educacional, entre aprendiz e facilitador é essencialmente recíproca, é uma troca de experiências, um diálogo. A sociedade na qual um indivíduo se instrui em grau mais elevado, já não é mais a mesma. Se o educador facilitador dá ao aprendiz a certeza de que deve partir dele mesmo, como sujeito, a aquisição do saber, a concepção do mundo que o educando produz será, necessariamente, crítica (PINTO, 2007).

Freire (2001) relata que a educação crítica considera os homens como seres em desenvolvimento, como seres inaca- bados, incompletos, em uma realidade igualmente inacabada. Os homens têm consciência de que são incompletos, e assim, nesse estar inacabados e na consciência que disso têm, encontram-se as raízes da educação como fenômeno puramente humano. O caráter inacabado dos homens e o caráter evolutivo da realidade exigem que a educação seja uma atividade contínua. Conforme afirma Abreu (2006), nós nunca estamos diante de pessoas prontas e também não o somos. Ao contrário, é no relacionamento com o outro que vamos nos construindo como pessoas realmente humanas.

$\mathrm{O}$ aprendizado do adulto é direcionado para seus interesses. A maturidade do adulto lhe proporciona condiçóes de tomar decisôes a partir de suas experiências vivenciadas (positivas ou negativas). O adulto prefere aprender para resolver problemas e desafios, a simplesmente aprender um assunto (BELLAN, 2005).

Considerando que o conceito de facilitação está diretamente relacionado com a chamada aprendizagem autodirigida, cabe ao facilitador, fomentar o crescimento, o desenvolvimento e a aprendizagem. $\mathrm{O}$ aprendiz sente a necessidade de crescer e o facilitador clarifica as suas necessidades, motivaçóes e objetivos. O facilitador ajuda o aprendiz a controlar este processo, criando clima e ambiente favoráveis. Finalmente, ao combinar as experiências do aprendiz com situaçóes concretas, o facilitador também contribui para resolver problemas (FINGER, 2003).

Segundo Knowles (2005), o facilitador ideal é aquele que: vê o aprendiz como um ser humano capaz de auto direcionar-se, capaz de cuidar do seu próprio crescimento; concebe a aprendizagem do adulto como um processo de auto-direcionamento; considera que a aprendizagem é mais significativa, se decorrer de motivação intrínseca; cria um clima de aprendizagem facilitada, caracterizado pela cordialidade, confiança mútua, respeito, interesse e informalidade, isto é, não diretividade. Para Libâneo, 2007 as práticas educativas não se restringem à escola ou à família.

Ainda Knowles (2005) considera que o papel do facilitador é o da pessoa-recurso para o aprendiz auto-dirigido; envolve o aprendiz na definição dos objetivos, sempre com o propósito de que estes sejam para ele significativos; desenvolve experiências seqüenciais de aprendizagem, que leve em conta semelhanças de grupos e diferenças individuais, como princípios organizadores dos processos de aprendizagem e, por fim, seleciona técnicas e materiais que envolvam ativamente o aprendiz no seu processo de auto-questionamento.

Segundo Bellan, (2005, p 56):

O papel do facilitador é apresentar as informações através de técnicas de ensino e criar um ambiente propício para a aprendizagem. A pessoa que quer trabalhar no ensino de adultos com eficiência precisa se colocar no mesmo plano de aprendizagem dos alunos, permitindo que haja troca de informações e experiências e assim desenvolver-se com eles. 
Utilizar as técnicas adequadas ao ensino de adultos, traçar um bom planejamento, organizar seu curso e avaliar principalmente sua atuação neste processo são aspectos fundamentais para o sucesso da tarefa de facilitador.

Toda atividade humana é regida pela eficácia, mas a ação não leva necessariamente ao sucesso. $\mathrm{Na}$ maioria dos casos, os resultados pretendidos só são atingidos na medida em que os erros podem ser corrigidos e evitados no decorrer da ação. Assim, toda ação produz duas espécies de efeitos sobre o que se procura: os efeitos desejados e os não desejados. São os encadeamentos de operaçóes e as regras e condiçóes a respeitar, que levarão aos efeitos pretendidos (MALGLAIVE, 2003). Do ponto de vista do indivíduo, as probabilidades de conceber a aprendizagem diferenciada depende de sua posição no contexto social, da natureza do seu trabalho e do valor atribuído a estes pelos interesses de sua consciência social (PINTO, 2007).

Falar de atividades de aprendizagem é também falar dos objetivos que se pretende atingir. Estes objetivos são os conteúdos, os saberes de qualquer natureza de que o aprendiz deve se apropriar. Acredita-se que os conteúdos de formação devem ser construídos e reconstruídos sem cessar, em função $\mathrm{da}$ diversidade de horizontes, que devem ser atingidos e da heterogeneidade das situaçóes, a partir das quais os aprendizes deverão atingi-las (MALGLAIVE, 2003).

Esta questão se refere ao adulto em condiçôes primárias de cultura, especialmente o adulto não alfabetizado ou semi-alfabetizado. Todavia, o que é realmente significativo é que ignora as causas de sua condição de desconhecimento cultural e de pobreza (PINTO, 2007).

Segundo Abreu (2006), mais importante que as informaçóes em si, mas o ato de transformá-las em conhecimento. As informaçóes são os tijolos e o conhecimento o edifício que construímos.

DeAquino (2007, p 102), alerta que:

De maneira geral, a não ser que isso seja especificamente relevante, deve-se evitar confiar somente na mídia para obter informaçóes: existem muitas opinióes que são tomadas como fato.

A mesma cautela deve ser aplicada à informação obtida na internet. Qualquer pessoa pode publicar informaçôes na internet, o que significa que existe muita orientação equivocada e informação imprecisa junto com informação boa e confiável.

$\mathrm{Na}$ verdade o real é sempre mais complexo do que o conhecimento que a teoria fornece dele, mesmo sendo ela científica (MALGLAIVE, 2003).

É necessário aprender os elementos básicos do saber ler e escrever; mas estes saberes ainda que fundamentais e indispen- sáveis, só valem por seu significado instrumental, por aquilo que possibilita ao aprendiz chegar a saber (PINTO, 2007).

Os saberes não são rígidos nem definitivamente ligados a uma intenção única. $\mathrm{O}$ processo de inclusão consiste numa decomposição e recomposição virtual do ato modular. O repertório dos saberes de um ser humano é, pois, constituído não somente por atos disponíveis, uma vez que foram experimentados e bem sucedidos em determinadas situaçóes, mas ainda por atos potenciais que permitem fazer face a novas situações (MALGLAIVE, 2003).

$\mathrm{O}$ adulto tem modo diferente de aprender de uma criança. Para que o aprendizado seja efetivo, é necessário aplicar teorias e técnicas adequadas. Tudo o que é feito com planejamento, traz resultados mais efetivos (BELLAN, 2005).

O método é de capital importância na aprendizagem de adultos, uma vez que já possuem consciência formada. Deve-se despertar nele a necessidade de instruir-se, a fim de viver com melhor qualidade de vida. Deve-se partir de elementos que compõem a realidade autêntica do aprendiz, seu mundo de trabalho, suas relaçôes sociais, suas crenças, valores, hábitos, gostos artísticos, etc. (PINTO, 2007).

A sociedade empreende a aprendizagem de adultos, para integrá-los num nível de produção ideal. Isto não se trata de dever moral ou obra de caridade e sim, uma exigência social. A aprendizagem de adultos é uma necessidade generalizada, alcançando homens e mulheres em todas as idades (PINTO, 2007).

Em estudo realizado, com aval de comitê de Ética, na Associaçấo dos aposentados e pensionistas de Volta Redonda (AAP-VR), sendo: um no Centro Gerontológico José Maria Taylor e outro no Centro de Saúde Sebastião Pinheiro Bastos (CARVALHO et al, 2009), envolvendo adultos e idosos, respectivamente, no ano de 2006, evidenciou-se uma grande incidência de sobrepeso nas populaçóes estudadas. Estes dados foram obtidos através do cálculo do Índice de Massa Corporal (IMC) e da Circunferência Abdominal (CA). Através da análise desses dados, concluiu-se que a população estudada, apresentava uma carência de informaçôes nutricionais, mesmo com o advento da utilização de sítios da internet, onde se obtem informaçôes superficiais ou mesmo aprofundadas sobre os diversos assuntos.

Muitos autores sugerem que estamos na era da comunicação. Sabemos que a mídia tem evoluído frequentemente e que a cada dia um número maior de brasileiros, passa a ter contatos via internet. Náo se pode ignorar o valor deste recurso, porém este meio de comunicação ainda é privilégio de apenas uma parcela da população.

A comunicação é um problema considerável no nosso país, especialmente nas comunidades de menor poder aquisitivo. Com vistas a esta realidade, faz-se necessário um trabalho contínuo de educação informal, levando informa- 
çôes de todas as áreas e a toda a população, especialmente, as que promovem um melhor estado de saúde. A promoção da saúde em qualquer etapa da vida é um processo que pode afetar positivamente a qualidade de vida de uma população (CARVALHO et al, 2010).

Considerando que a alimentação é um dos fatores primordiais à saúde, torna-se necessário uma maior divulgação de informaçóes básicas que possam contribuir para formação de hábitos alimentares saudáveis, bem como, para a correção de possíveis erros que vem sendo cometidos.

Pequenas alterações nas atividades diárias e nos hábitos alimentares podem retardar muitos problemas e sintomas associados ao processo de envelhecimento, além de prolongar a saúde e o bem estar nos anos seguintes.

Assim, um programa regular de atividade física, associado a uma alimentação adequada em termos quantitativos e qualitativos, são intervençóes que melhoram ou retardam o curso de muitas doenças crônicas, oferecendo aos idosos maiores perspectivas de uma velhice feliz (CARVALHO et al, 2009).

Mais importante que as informaçôes em si, está o ato de transformá-las em conhecimento.

Como objetivos deste trabalho procuramos promover reflexão sobre o ensino não formal contínuo, visando contribuir para a melhoria dos hábitos das comunidades, propondo medidas que possam contribuir para uma melhor qualidade de vida; confeccionar ferramentas didáticas informativas como: folders, cartilhas e livros didáticos sobre alimentação/ nutrição e despertar nos educadores, instrutores e multiplicadores de conhecimentos, a importância de melhorar a qualidade de vida através do processo educativo dos adultos.

\section{METODOLOGIA}

Este estudo foi desenvolvido através de levantamento bibliográfico por meio de leitura, pesquisa, compilaçóes e colagens de autores nacionais e internacionais, obtidos em livros e artigos que abordam os temas Educaçáo de Adultos e Educação Nutricional.

É importante salientar a escassez de literatura no que se refere à educaçáo nutricional, especialmente no que se trata de conceitos básicos sobre a alimentação, ficando o pessoal de nível técnico e leigo, que se interessa pelas questóes nutricionais, sem uma opção de literatura onde possa esclarecer suas dúvidas.

Tendo em vista o pouco material existente sobre o tema em questão, é necessário o desenvolvimento de materiais didáticos destinados a subsidiar os profissionais que atuam com adultos, permitindo um trabalho mais eficiente.

Uma cartilha informativa foi elaborada, com o título "Alimentação saudável”, destinada a levar os conhecimentos básicos sobre os componentes alimentares, nutrientes, presentes nos alimentos, bem como o fracionamento de uma ração alimentar.

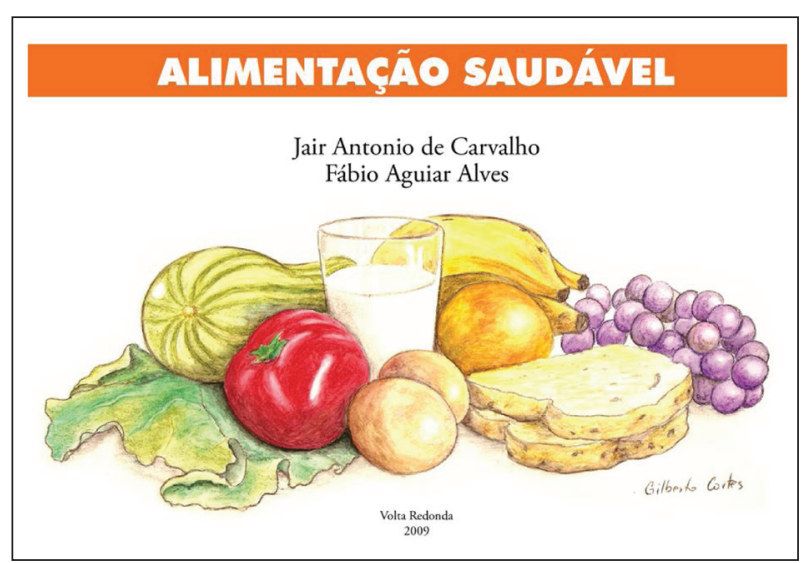

Foi feita uma pesquisa de validação da referida ferramenta, com o aval de um Comitê de Ética, e a coleta de dados foi desenvolvida na Escola Municipal Mário Villani.

Com a presença de 104 participantes, pais de alunos da referida escola, foi feita a apresentação e exposição do conteúdo da Cartilha, pelo autor do trabalho. Em seguida os participantes preencheram um questionário de avaliação do trabalho apresentado, sob a orientação da Nutricionista Aline Freire Duarte e da Técnica de Enfermagem Marise Maria Gomes Freire, onde foram avaliados os seguintes intens: apresentação, relevância, clareza e adequação.

No mesmo questionário foi solicitada uma auto-avaliação em que foi perguntado como eram os conhecimentos dos participantes antes e depois da exposição.

\section{RESULTADOS}

Quanto à validade da ferramenta didática elaborada, os dados obtidos na pesquisa são: 68,26\% de excelência para a variável adequação; $65,88 \%$ para relevância; 51,92\% para apresentação e 50,96 para clareza, representadas no seguinte gráfico:

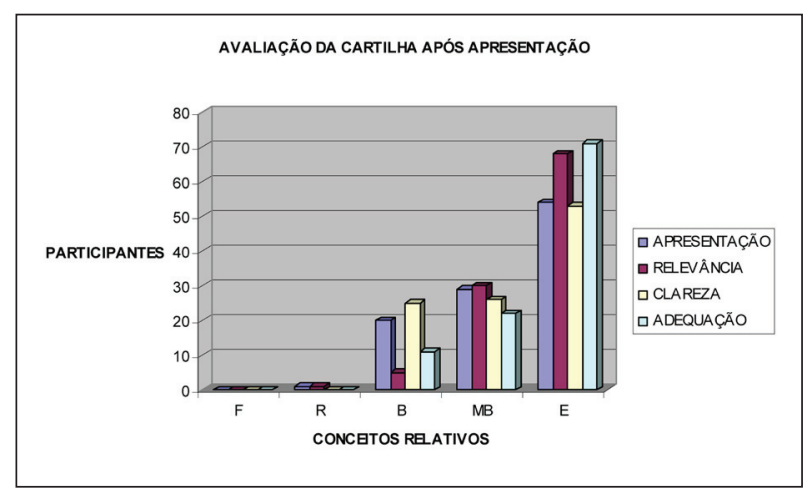

Gráfico I Avaliação da cartilha após a apresentação

(Legenda: $\mathrm{F}=$ fraco, $\mathrm{R}=$ regular, $\mathrm{B}=$ bom, $\mathrm{MB}=$ muito bom e $\mathrm{E}=$ Excelente) 
No mesmo questionário foi solicitada uma auto-avaliação em que foi perguntado como eram os conhecimentos dos participantes antes e depois da exposição, obtendo-se: $75,96 \%$ classificaram seus conhecimentos como excelentes (E), após a exposição da ferramenta didática, enquanto que $24,03 \%$ classificaram com muito bom (MB) seus conhecimentos após a apresentação. Mais detalhes deste item da pesquisa pode ser avaliado no gráfico a seguir.

\section{Gráfico II Auto avaliaçáo sobre o conteúdo da cartilha}

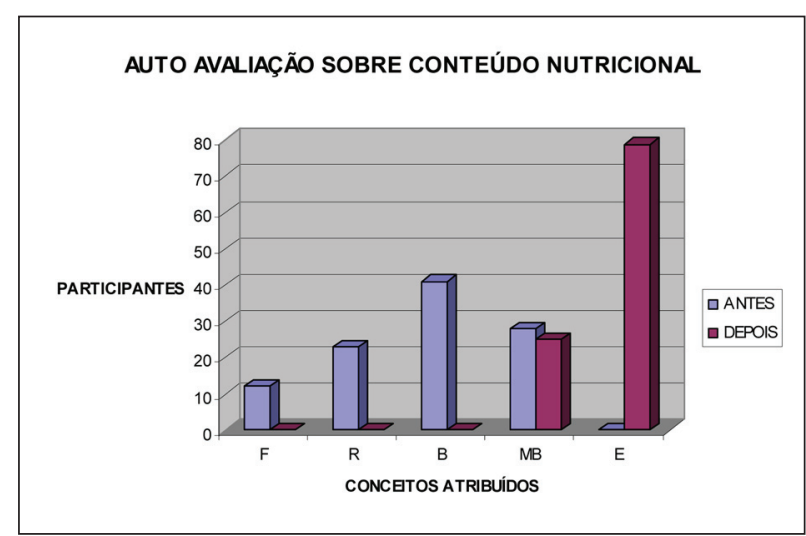

(Legenda: $\mathrm{F}=$ fraco, $\mathrm{R}$ = regular, $\mathrm{B}$ = bom, $\mathrm{MB}=$ muito bom e $\mathrm{E}=$ Excelente)

\section{DISCUSSÃO}

Durante a realização deste trabalho, foi possível observar que o desenvolvimento ocorrido no ensino de ciências, tanto do ponto de vista da teoria quanto da prática, se deve, primordialmente, à história, à filosofia e a sociologia. Acreditamos que o trabalho educativo em ciências deve sempre focar teoria e prática, levando o aprendiz a interagir com os conhecimentos assimilados.

Paralelamente, observamos que a educação de adultos tem merecido especial atenção da UNESCO desde a sua criação, especialmente no que se refere à alfabetização e a educação básica de adultos. No Brasil a preocupação com a educação de adultos, não é somente dos últimos anos. Querubim (2005) relata que em 1908, no II Congresso Operário do Estado de São Paulo, foi sugerido e aprovado o apoio ao "Desenvolvimento Intelectual do Operariado", seguindo a tradição do sindicalismo britânico e alemão.

No Brasil, nas décadas de 70 e 80 a educação nutricional foi vista como prática repressora, reprovada por muitos. Educar em nutriçáo é tarefa complexa, implica em criar novos significados e sentidos para o ato de comer. $\mathrm{O}$ trabalho educativo deve contemplar teoria e prática, permitindo assim que o aprendiz vivencie na prática, o conceito teórico.

Discutir as questóes sobre a alimentação, especialmente com os jovens, é fator de grande importância na preven- ção da saúde na idade adulta. Sendo a escola importante instrumento na formação da cidadania, é oportuno utilizála como meio, para fazer chegar a todos os segmentos sociais os conceitos básicos para uma alimentação saudável, através de ferramentas didáticas claras, objetivas e de fácil entendimento. Para isso, foi construída a cartilha referida e aplicou-se o questionário para validação.

Após a tabulação dos resultados verificou-se que: as variáveis adequação e relevância obtiveram os melhores resultados, $68,26 \%$ e $65,88 \%$ respectivamente. Para as variáveis apresentação e clareza, os resultados foram 51,92\% e $50,96 \%$, respectivamente. No mesmo questionário foi solicitada uma auto-avaliação, onde foi perguntado como eram os conhecimentos dos participantes antes e depois da exposição. Com relação a este item da pesquisa, verificou-se que: antes da apresentação 12 participantes $(11,53 \%)$ se avaliaram como fracos, 23 participantes $(22,11 \%)$ se avaliaram como regulares, 41 participantes $(39,42 \%)$ se avaliaram como bons e 28 participantes $(26,92 \%)$ se avaliaram como muito bons enquanto que, após a apresentação, 79 dos 104 participantes (75,96\%) classificaram seus conhecimentos como excelentes; enquanto que 25 dos participantes $(24,03 \%)$ classificaram seus conhecimentos como muito bons.

Portanto observa-se com a avaliação que o grupo pesquisado está ávido de informações no que se refere aos aspectos nutricionais e que há uma carência em eventos educacionais não-formais a fim de levar informaçôes a estas comunidades.

\section{CONCLUSÃO}

O trabalho educativo em ciências deve focar teoria e prática, levando o aprendiz a interagir com os conhecimentos assimilados. A democratização do ensino é condição fundamental para o desenvolvimento de uma nação. É de fundamental importância o reconhecimento da escola como instrumento de formação da cidadania.

A educação é fator fundamental para o pleno uso de seus direitos como cidadão, contribuindo também para a adoção de um estilo de vida saudável.

Uma alimentação inadequada, a médio e longo prazos, pode contribuir para o aparecimento de vários problemas para a saúde, bem como favorecer o aparecimento das doenças crônico-degenerativas como as síndromes metabólicas e obesidade.

A falta de informação é um dos fatores que comprometem consideravelmente a saúde de uma população. Portanto, oferecer informaçóes nutricionais à população, através de palestras educativas (oficinas), produção de material de divulgação (folders) e desenvolvimento de material 
didático, destinado a levar conhecimentos básicos sobre a alimentação, é imprescindível para que se tenha uma população com mais qualidade de vida e intervenções específicas devem ser feitas, quando o grupo apresenta algum desvio nutricional a fim de corrigir e prevenir futuros problemas que possam comprometer a saúde das pessoas.

As comunidades são ávidas de informaçóes, especialmente quando elas são despertas para o quanto essas informaçôes lhes fazem falta. Assim, campanhas devem ser desenvolvidas no sentido de levar, às populaçóes, conhecimentos básicos de saúde, através de medidas simples, focando as questôes de: higiene pessoal e ambiental, alimentação saudável, saúde oral e questão postural, entre outras.

\section{REFERÊNCIAS BIBLIOGRÁFICAS}

1. ABREU, A. S., A arte de argumentar - Gerenciando razão e emoçáo. Cotia, Ateliê Editorial, 2006.

2. BELLAN, Z. S., A andragogia em ação: como ensinar adultos sem se tornar maçante. Santa Bárbara d'Oeste, SOCEP Editora, 2005.

3. CARVALHO J.A. et al, Perfil Nutricional Associado ao Índice de Obesidade de Idosos do Centro de Saúde Sebastião Pinheiro Bastos, AAP-VR, Volta Redonda, RJ. Rev. Práxis, ano 1, n.1, Volta Redonda, 2009.

4. EDUCAÇÃO EM SAÚDE BUCAL: Uma Abordagem Reflexiva em Prol da Qualidade de Vida, Rev. Práxis, ano II, n.3, Volta Redonda, 2010.

5. DEAQUINO, T. C. E., Como aprender andragogia: andragogia e as haabilidades de aprendizagem. São Paulo, PearsonPrentice Hall, 2007.
6. FINGER, M., ASÚN, J. M., A educaçáo de adultos numa encruzilhada: aprender a nossa saída. Porto Portugal, Porto Editora LDA, 2003.

7. FREIRE, P., Conscientizaçáo. Teoria e prática da libertação: uma introduçáo ao pensamento de Paulo Freire. 3 ed. São Paulo, Centauro. 2001.

8. KNOWLES, M. S., The Adult Learner: The Definitive Classic in Adult Education and Human Resource Development. 6th ed. San Diego, California, USA, Elsevier, 2005

9. LIBÂNEO, J. C., Pedagogia e Pedagogos, Para que?, Rev. Cadernos de Pesquisa, Vol. 37, n.131, São Paulo, 2007.

10. MALGLAIVE, G. Ensinar adultos. Porto - Portugal, Porto Editora LDA, 1995.

11. PEREIRA A.V. et al, GRUPOS DE EDUCAÇÃO EM SAÚDE: Aprendizagem permanente com pessoas soro positivas para o HIV, Rev. Trab. Educ. Saúde, Vol. 9, n.1, São Paulo, 2011.

12. PINTO, A. V., Sete liçóes sobre educaçáo de adultos. 15 ed. São Paulo, Cortez Editora., 2001.

13. VAZ, A. C. R. Programas açóes educativas complementares. Anais do VIII Encontro de Extensáo da UFMG. Belo Horizonte, 2005. 